\title{
Direct effects of a domain-specific subjective age measure on self-reported physical activity - Is it more important how old you are or how old you feel?
}

\section{BACKGROUND}

Research has shown that physical activity is important for healthy aging. At the same time, physical activity and different age factors (chronological and subjective age measures) are interrelated. The present study investigated whether subjective physical age and chronological age are significantly correlated with physical activity over time.

\section{PARTICIPANTS AND PROCEDURE}

A study design with baseline assessment and a 4-week follow-up period was conducted with an online sample $(N=541)$, aged 25-78 years $(M=39.62, S D=10.74)$. Regression analysis with the enter method was used to predict subsequent physical activity by baseline predictors.

\section{RESULTS}

Subjective physical age correlates with chronological age $(r=-.34, p<.001)$. Subjective physical age predicted subsequent physical activity when controlling for baseline variables $(B=-.12, t=-2.43, p=.015)$ until past physical activity was entered $(B=-.06, t=-1.44, p=.150)$. The final model explained $33 \%$ of variance in subsequent physical activity.

\section{CONCLUSIONS}

Subjective physical age seems to be more important for physical activity than chronological age. This is an important finding as subjective physical age might be a target for interventions, to enable individuals to become more physically active. Future studies should investigate non-linear relationships between subjective physical age, social-cognitive predictors of physical activity and physical activity behavior.

\section{KEY WORDS}

subjective age; domain-specific measure; social cognitive predictors for behavior change; online study; self-reported physical activity

ORGANIZATION - 1: Institute for Social Medicine and Epidemiology, University of Lübeck, Germany · 2: Research Methods, Assessment and iScience, Department of Psychology, University of Konstanz, Germany · 3: Jacobs Center on Lifelong Learning and Institutional Development, Jacobs University Bremen, Germany

aUthors' Contributions - A: Study design - B: Data collection - C: Statistical analysis - D: Data interpretation .

E: Manuscript preparation · F: Literature search · G: Funds collection

CORRESPONDING AUTHOR - Julian Wienert, M.A., Institute for Social Medicine and Epidemiology, Universität zu Lübeck, Ratzeburger Allee 160, 23562 Lübeck, Germany, e-mail: julian.wienert@uksh.de

to Cite this ARTICLE - Wienert, J., Kuhlmann, T., \& Lippke, S. (2015). Direct effects of a domain-specific subjective age measure on self-reported physical activity - Is it more important how old you are or how old you feel? Health

Psychology Report, 3(2), 131-139. DOI: 10.5114/hpr.2015.51450

RECEIVED 06.03.2015 · REVIEWED 05.04.2015 · ACCEPTED 04.05.2015 • PUBLISHED 15.05.2015 


\section{BACKGROUND}

Maintaining a healthy lifestyle throughout the lifespan is an important factor in the prevention of chronic diseases (e.g., cardiovascular diseases: Archer \& Blair, 2011). A sufficient amount of physical activity contributes to such a lifestyle and has a positive impact on health, as suggested by the World Health Organization (WHO, 2010). The broader population is probably well aware of the benefits of reg-
Julian Wienert, Sonia Lippke Tim Kuhlmann, ular physical activity and risks of inactivity, but most do not meet common recommendations, though they might have the right intentions to engage in a more active lifestyle (Rhodes \& de Bruijn, 2013).

Engaging in and maintaining an active lifestyle receives special attention considering the advancing demographic changes in some societies, since active individuals report better physical and mental health (Bertheussen et al., 2011). In line with Salthouse (1991), some studies in the context of health behavior research provided support for his argument that chronological age alone might not be a suitable predictor to explain age-related effects in health behaviors, as long as other age concepts can also contribute to the explanation of age-related phenomena (e.g., decline in physical activity; cf. future time perspective: Gellert, Ziegelmann, Lippke, \& Schwarzer, 2012; residual life expectancy: Ziegelmann, Lippke, \& Schwarzer, 2006). One of these age concepts could be subjective age. Overall, subjective age seems to be a promising construct to investigate health and different health domains. This has already been shown on a correlational level for physical and mental health (Barak \& Stern, 1986; Kleinspehn-Ammerlahn, Kotter-Grühn, \& Smith, 2008) and in a crossed-lagged study with different health domains (i.e., physical health status, functional health, self-rated health, and mental health; Spuling, Miche, Wurm, \& Wahl, 2013), indicating that those who feel younger, irrespective of their chronological age, report better health in some domains. Furthermore, subjective age explained between $10 \%$ and $15 \%$ of variance in health in a study by Hubley and Hultsch (1994). Additionally, those who indicate a younger subjective age also seem to have higher intentions to engage in physical activity when self-efficacy is also high (Caudroit, Stephan, Chalabaev, \& Le Scanff, 2012).

The current study focused on subjective physical age, as a possible domain of subjective age, and investigated its predictive value in the explanation of physical activity as a starting point for future research. Social-cognitive models of health behavior change have been proven to provide successful means to engage in and maintain physical activity (cf. Conner \& Norman, 2005; Lippke \& Ziegelmann, 2008), especially when they consider strategies to cross the so-called intention-behavior gap (e.g., plan- ning: Schwarzer, 2008). One of these models is the Health Action Process Approach (HAPA; Schwarzer, 2008), which includes various social-cognitive predictors for health behavior change. Therefore, the social-cognitive predictors will be outlined further.

\section{PREDICTORS FOR HEALTH BEHAVIOR}

Besides the assumed modeling of physical activity, the HAPA provides information about central social-cognitive predictors for the adoption and maintenance of health behaviors, such as physical activity. In general the HAPA separates them into motivational and volitional constructs. Motivational constructs focus on the formation and implementation of intentions to engage in the target behavior. Such constructs are risk perception, and positive and negative outcome expectations. These are associated with a future perspective on the target behavior and ideally benefit the formation of intentions to engage in the behavior (Schwarzer, 2008). Volitional constructs represent self-regulatory efforts and help to translate good intentions into actual behavior. Such constructs include action planning as a means to engage in the behavior, and coping planning to deal with anticipated barriers by building counter strategies and subsequent mindsets (Schwarzer, 2008). Gholami, Knoll, and Schwarzer (submitted for publication) reported small to medium effect sizes on health behavior change for all HAPA components, except risk perception. This was also shown specifically for physical activity in three longitudinal studies with rehabilitation samples (Schwarzer, 2008) and for self-efficacy and planning (e.g., Kreausukon, Gellert, Lippke, \& Schwarzer, 2012; Koring et al., 2012; Mullen, McAuley, Satariano, Kealey, \& Prohaska, 2012).

\section{SUBJECTIVE AGE}

Westerhof and Wurm (2015) described the origins of subjective age research (focusing on ideal age) in self and identity research. This especially included processes of self-consistency and self-enhancement, suggesting that both processes shape age identities. Self-consistency reflects the motive of staying the same stable person over time, whereas self-enhancement reflects maintaining a positive self-image while focusing on self-esteem as a positive illusion (Westerhof \& Wurm, 2015). They state that "individuals are able to maintain consistency by assimilating new experiences into their existing self-concepts and thereby identifying with the younger age they used to be" (Westerhof \& Wurm, 2015, p. 148). This would provide especially older adults with a positive bias towards younger ages, as this fosters the identification with younger ages and age groups by enhancing their 
self-esteem and well-being - especially in cultures that devalue old age (cf. Weiss \& Lang, 2009, 2012).

Additionally, previous research describes subjective age as the outcome of a self-evaluative process of distal reference points in the past, present, and future (Montepare, 2009) and is usually operationalized as the difference between chronological age and the indicated perceived age, i.e. the age people perceive themselves to be (Barak \& Stern, 1986; Kleinspehn-Ammerlahn et al., 2008). Stephan, Chalabaev, Kotter-Grühn, and Jaconelli (2013) showed that subjective age can be manipulated via downward social comparison. This would complement the suggested internal self-evaluation with an external, comparative evaluation. Furthermore, those who feel subjectively younger seem to be less susceptible to negative aging stereotypes (Eibach, Mock, \& Courtney, 2010), and therefore might not behave in a stereotypical way. Subjective age also seems to be associated with health and well-being, which was shown by several studies. Those who feel younger reported a better health or higher well-being in different domains and better outcomes on other health indicators (Demakakos, Gjonca, \& Nazroo, 2007; Kotter-Grühn, Kleinspehn-Ammerlahn, Gerstorf, \& Smith, 2009; Westerhof \& Barrett, 2005). Furthermore, a higher self-efficacy to cope with stressful life events was reported to be associated with a younger subjective age, highlighting the possible importance for self-efficacy in a health behavior context (Boehmer, 2007).

\section{AIMS}

The present study focused on exploratory testing of hypotheses by building on past findings from a study by Caudroit and colleagues (2012) which investigated the influence of subjective age on the formation of intentions to engage in physical activity. We explored differences in chronological and subjective physical age when predicting self-reported physical activity using motivational and volitional components of the HAPA as the theoretical outline to provide a more detailed understanding of how chronological and subjective age might differ in predicting physical activity. This was done by measuring domain-specific subjective age via subjective physical age.

The current study also draws on results from research on other domain specificity of measures used in health psychology in various contexts. For measures such as self-efficacy (Maibach \& Murphy, 1995) and locus of control (Lachman, 1986) domain specificity proved to increase validity and interrelation with other measures. Thus, the current study used subjective physical age as a domain-specific measure of subjective age. We suggest that this might also provide similar benefits for our measure, namely a higher explanatory value and a higher sensitivity for changes in one domain (cf. Lachman, 1986; Maibach \& Murphy, 1995).

The present study focused on testing whether feeling physically younger is associated with higher levels of self-reported physical activity. Specifically, we investigated whether a high intercorrelation between chronological age and subjective physical age exists (Hypothesis 1) to test for comparable effects between subjective physical age and physical activity, as already reported for general subjective age and physical activity (cf. Barak \& Stern, 1986). Given the past results concerning general subjective age and health outcomes, we also expected that subjective physical age would show an inverse direct relationship with physical activity, indicating that people who feel physically younger show an increase in self-reported physical activity (Hypothesis 2). Furthermore, we hypothesized that subjective physical age can function as a predictor of self-reported physical activity while also controlling for chronological age (Hypothesis 3).

\section{PARTICIPANTS AND PROCEDURE}

\section{SAMPLE AND PARTICIPANT SELECTION}

This study was carried via online survey completion for which participants from various sources were recruited (e.g., newspaper, flyer, radio). After informed consent was given, participants followed a link to a self-administered questionnaire (t1). After four weeks, they received an e-mail invitation to answer a follow-up online questionnaire (t2). The survey was carried out using the open access software dynQuest, an easy-to-use, platform-independent, and reliable package to assess data online (Rademacher \& Lippke, 2007).

In total, 2,201 potential participants responded to the initial website with the questionnaire. Warmup questions were applied at $\mathrm{t} 1$ (first six questions) to ensure sincerity of participation, and to reduce the impact of dropout from the study itself (Reips, 2002). Those questions focused on the perceived severity and vulnerability to suffer from a chronic health impairment (e.g. diabetes). In total, 158 participants decided to quit during the warm-up phase, and were excluded from the subsequent analyses. Furthermore, 481 participants were excluded from subsequent analyses because they did not meet the inclusion criteria (missing values on relevant constructs at $\mathrm{t} 1$ and $\mathrm{t} 2$ ). Outlier analysis for inconsistent replies was performed (three standard deviations of subjective age measures), excluding 21 more participants. The cross-over point of subjective age at 25 years was applied to the data. This cross-over point represents the turning point when changing cognitions with the tendency to report an older subjective age towards a younger subjective age (cf. Galambos,
Predicting self-reported physical activity via subjective physical age 


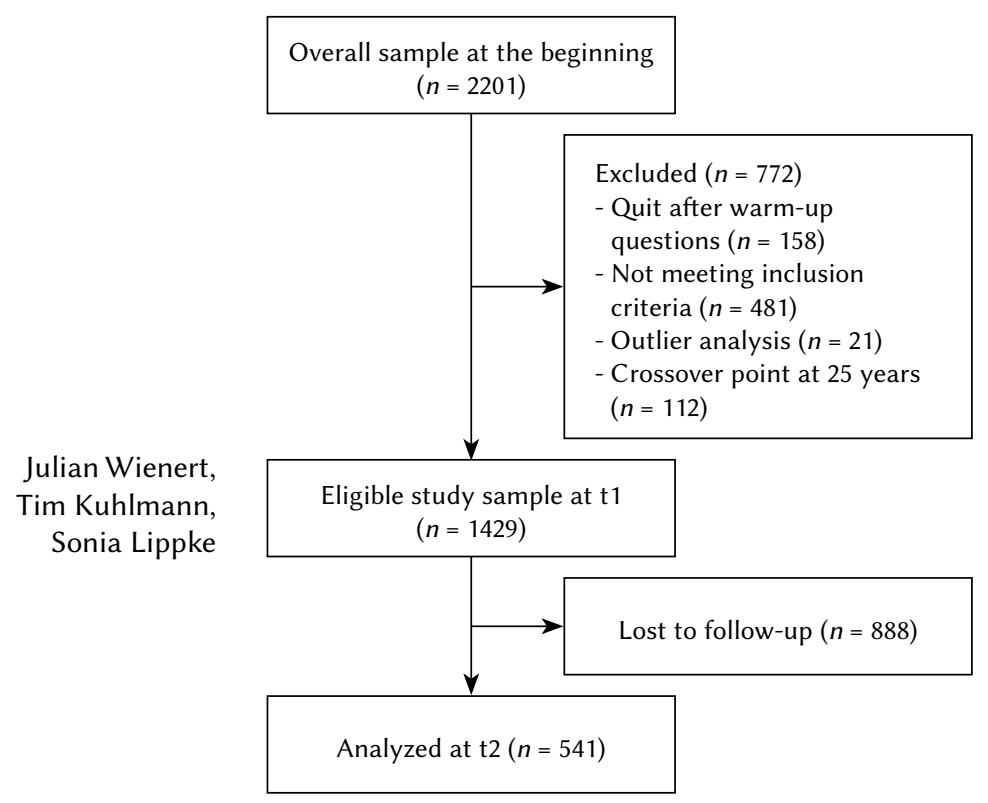

Figure 1. Study exclusion and dropout.

Turner, \& Tilton-Weaver, 2005). This was done to ensure the same meaning of the subjective age measure used across the sample and resulted in 112 study participants being excluded. During the 4-week period between $\mathrm{t} 1$ and $\mathrm{t} 2,888$ participants dropped out of the study (see Figure 1). Besides the exclusion criteria, no specific inclusion criteria were set.

The final sample consisted of $542(24.60 \%)$ participants for the analyses to predict physical activity, aged 25 to 78 years, with a mean age of $M=39.70$ $(S D=10.85)$ to draw general conclusions over a wide life-span. Of the initial sample, $71.40 \%$ were women, $58.40 \%$ were living with a partner, $80.00 \%$ had completed senior high school, and $61.40 \%$ of them held a university degree.

Significant differences $(p<.050)$ between study dropout and study participants occurred in terms of gender (more men dropped out), school education (more participants with lower education dropped out), vocational education (more participants with a lower vocational qualification dropped out), coping plans (participants who left the study made more use of plans), and self-reported physical activity (participants who left the study were less active) using $t$-test statistics with dummy variables and $\chi^{2}$ test.

\section{INDEPENDENT MEASURES}

Past studies revealed the significant role of predictors such as self-efficacy for physical activity and planning on health behavior (e.g., Kreausukon et al., 2012; Koring et al., 2012; Mullen et al., 2012). These predictors were included in the subsequent analyses as independent variables, to show the additional predictive value by using chronological and subjective physical age. The independent variables are stated below.

Age measures. Age measures were differentiated into chronological age and subjective physical age. Besides the usual question "How old are you?", participants were asked "How old do you feel physically?”. In line with previous subjective age research, a difference score for both measures was calculated (perceived age - chronological age $=$ subjective age), resulting in a subjective physical age score. A negative value represents a youthful subjective age, and a positive value represents an older subjective age (Kleinspehn-Ammerlahn et al., 2008).

Health status. Current health status was assessed via a single item from the German SF-12 (Bullinger \& Kirchberger, 1998) asking, "In general, would you say your health is", recoding the answer format for the analysis $(1=$ poor, $2=$ fair, $3=$ good, $4=$ very good, 5 = excellent).

Self-efficacy. Self-efficacy refers to "...beliefs in one's capabilities to organize and execute the courses of action required to produce given levels of attainments" (Bandura, 1998). Three types of self-efficacy were assessed, each with three items: motivational (e.g., "I am confident that I can be physically active for 30 minutes on 5 days a week"), maintenance (e.g., "I am confident that I can do at least 30 minutes of strenuous physical activity 5 days a week, even though I need a few attempts"), and recovery self-efficacy (i.e., "I am confident that I can be physically active for 30 minutes on 5 days a week again, even though I adapted my concrete plans to do so several times"). Participants used the response set $1=$ totally disagree, 2 = disagree, 3 = agree, 4 = totally agree for each item. Despite the theoretical separation into three facets, factor analysis revealed a single factor structure with a Cronbach's $\alpha$ of .87 .

Intention. Participants were asked to rate their intentions to engage in regular physical activity. Intentions were assessed according to suggestions by Nigg (2005), addressing three different intensity levels of physical activity. "I intend to perform the following activities at least 5 days per week for 30 minutes...": (1) “...strenuous (rapid heartbeats, sweating) physical activities”; (2) “...moderate (not exhausting, light perspiration) physical activities"; and (3) "...mild (minimal effort, no perspiration) physical activity”. Participants used the response set $1=$ totally disagree, 2 = disagree, 3 = agree, 4 = totally agree for each item. This scale was aggregated including all intensities to obtain an index that reflects the broadness of the construct (discriminant validity; Lippke, Ziegelmann, Schwarzer, \& Velicer, 2009).

Planning. Three action plan items were used to specify the concrete performance and the setting related to the behavior, stating, "I already made detailed plans of when and how often I would like to be physically active". Three coping plan items were used 
to determine whether people were able to deal with certain barriers while performing the behavior, stating, "I have already made detailed plans of what I can do in difficult situations to stick to my goals." Participants used the response set $1=$ totally disagree, 2 = disagree, 3 = agree, 4 = totally agree for each item. Factor analysis revealed a single factor structure with a Cronbach's $\alpha$ of .86 .

\section{DEPENDENT MEASURES}

Behavior. Physical activity was assessed by asking how often $(1=$ less than 1 time a week for 30 minutes, $2=$ at least 1 time a week for 30 minutes or more, $3=$ at least 3 times a week for 30 minutes or more, $4=$ at least 5 times a week for 30 minutes or more) within the last month the person had been active in terms of physical fitness (e.g., going to the fitness studio), active commuting (e.g., taking the bicycle instead of the bus or car) and physical activities in daily life (e.g., gardening). All three indicators correlated significantly at $p<.010$ and were aggregated to represent the broadness of the construct (discriminant validity; Lippke et al., 2009).

\section{DATA ANALYSIS}

Pearson's correlation coefficients were determined to examine the relationship between age measures and all variables used in the following analysis and to ex- plore intercorrelations and possible problems with multicollinearity. Hierarchical multiple regression analysis with the 'enter method' for the independent measures at $\mathrm{t} 2$ was applied to test further hypotheses using SPSS 21.0 software. In the first step a standard set of socio-demographic variables was included to adjust for gender, marital status, education status, employment status, and health status. Furthermore, the variance inflation factor (VIF) and the tolerance were checked for multicollinearity. No predictor raised serious concern for multicollinearity regarding a cut-off at 10 for the VIF and tolerance values below 0.2 (Field, 2009).

\section{RESULTS}

Chronological age showed a significant interrelation with subjective physical age $(r=-.34, p<.001)$. Additionally, subjective physical age significantly correlated with physical activity at both measurement points as well ( $\mathrm{t} 1: r=-.24, p<.001 ; \mathrm{t} 2: r=-.21$, $p<.001)$. Furthermore, subjective physical age was significantly interrelated with all other variables related to the HAPA (see Table 1).

Hierarchical regression steps were as follows: Step 1 included control variables (gender, marital status, school education, vocational training, employment status, and health status). Step 2 included chronological age, step 3 included subjective physical age, step 4 included self-efficacy, step 5 included intention, step 6 planning, and step 7 past physical activity (Table 2).

Table 1

Intercorrelations, means, and standard deviations for age measures, self-efficacy, and plans for physical activity $(N=541)$

\begin{tabular}{|c|c|c|c|c|c|c|c|c|c|c|c|}
\hline & 1 & 2 & 3 & 4 & 5 & 6 & 7 & 8 & $M$ & $S D$ & Range \\
\hline $\begin{array}{l}\text { Health status } \\
\text { t1 }\end{array}$ & 1.00 & & & & & & & & 3.36 & 0.90 & $1-5$ \\
\hline $\begin{array}{l}\text { Chronological } \\
\text { age t } 1\end{array}$ & -.06 & 1.00 & & & & & & & 39.62 & 10.74 & $25-78$ \\
\hline $\begin{array}{l}\text { Subjective } \\
\text { physical age } \\
\text { t1 }\end{array}$ & $-.43^{* * *}$ & $-.34^{* * *}$ & 1.00 & & & & & & -2.55 & 6.14 & $-19-20$ \\
\hline $\begin{array}{l}\text { Self-efficacy } \\
\text { t1 }\end{array}$ & $.23^{* * *}$ & .04 & $-.20 * * *$ & 1.00 & & & & & 2.73 & 0.66 & $1-4$ \\
\hline Intention t 1 & .05 & $.11^{*}$ & $-.10^{*}$ & $.38^{* * *}$ & 1.00 & & & & 2.54 & 0.78 & $1-4$ \\
\hline Planning t1 & $.20^{* * *}$ & .03 & $-.14^{* *}$ & $.38^{* * *}$ & $.28^{* * *}$ & 1.00 & & & 2.56 & 0.75 & $1-4$ \\
\hline $\begin{array}{l}\text { Past physical } \\
\text { activity (t1) }\end{array}$ & $.27^{* * *}$ & .05 & $-.24^{* * *}$ & $.32^{* * *}$ & $.25^{* * *}$ & $.36^{* * *}$ & 1.00 & & 2.12 & 0.66 & $1-4$ \\
\hline $\begin{array}{l}\text { Subsequent } \\
\text { physical } \\
\text { activity (t2) }\end{array}$ & $.24^{* * *}$ & .01 & $-.21^{* * *}$ & $.27^{* * *}$ & $.19^{* * *}$ & $.33^{* * *}$ & $.53^{* * *}$ & 1.00 & 2.25 & 0.68 & $1-4$ \\
\hline
\end{tabular}


Hierarchical multiple regression analysis predicting physical activity after 4 weeks $(N=541)$

\begin{tabular}{|c|c|c|c|c|}
\hline Predictor & $B$ & $S E B$ & $\beta$ & $\Delta R^{2}$ \\
\hline Step 1 & & & & $.08^{* * *}$ \\
\hline \multicolumn{5}{|l|}{ Control variables } \\
\hline Gender & -.07 & .06 & -.05 & \\
\hline Marital status & .01 & .05 & .01 & \\
\hline School education & -.05 & .03 & -.08 & \\
\hline Vocational training & -.01 & .04 & -.01 & \\
\hline Employment status & .04 & .02 & $.09^{*}$ & \\
\hline Health status & .20 & .03 & $.26^{* * *}$ & \\
\hline Step 3 & & & & $.01^{* *}$ \\
\hline \multicolumn{5}{|l|}{ Control variables ${ }^{1}$} \\
\hline Chronological age & $<.01$ & $<.01$ & -.04 & \\
\hline Subjective physical age & -.02 & .01 & $-.15^{* *}$ & \\
\hline Step 6 & & & & $.04^{* * *}$ \\
\hline \multicolumn{5}{|l|}{ Control variables ${ }^{1}$} \\
\hline Chronological age & $<.01$ & $<.01$ & -.06 & \\
\hline Subjective physical age & -.01 & .01 & $-.12^{*}$ & \\
\hline Self-efficacy & .10 & .05 & $.10^{*}$ & \\
\hline Intention & .06 & .04 & .06 & \\
\hline Planning & .21 & .04 & $.23^{* * *}$ & \\
\hline Step 7 & & & & $.14^{* * *}$ \\
\hline \multicolumn{5}{|l|}{ Control variables ${ }^{1}$} \\
\hline Chronological age & $<.01$ & $<.01$ & -.06 & \\
\hline Subjective physical age & -.01 & .01 & -.06 & \\
\hline Self-efficacy & .04 & .04 & .04 & \\
\hline Intention & .02 & .04 & .02 & \\
\hline Planning & .11 & .04 & $.12^{* *}$ & \\
\hline Past physical activity & .45 & .04 & $.44^{* * *}$ & \\
\hline$R^{2}$ & .33 & & & \\
\hline$N$ & 541 & & & \\
\hline
\end{tabular}

Julian Wienert, Tim Kuhlmann, Sonia Lippke

${ }^{1}$ Control variables are included in every step of the regression analysis. Steps 4 and 5 were excluded from the table to reduce the information. This information can be obtained from the authors.

\section{PREDICTING PHYSICAL ACTIVITY}

At step 1, control variables were entered into the model, of which only employment status $(B=.09$, $t=2.23, p=.026)$ and health status $(B=.26, t=6.20$, $p<.001)$ were significant. Chronological age entered the model at step $2(B=.01, t=0.27$, n.s.; not reported in Table 2) and subjective physical age at step $3(B=-.15, t=-2.89, p=.004)$. Self-efficacy entered the model at step $4(B=.21, t=4.87, p<.001$; not reported in Table 2$)$. Intention to engage in physical activity entered the model at step $5(B=.10$, $t=2.32, p=.021$; not reported in Table 2$)$, and planning at step $6(B=.23, t=5.30, p<.001)$.

Past physical activity entered the model at step 7 $(B=.44, t=10.58, p<.001)$. Until the sixth step of the model, subjective physical age was able to predict subsequent physical activity $(B=-.12, t=-2.43$, $p=.015)$ among employment status $(B=.10$, $t=2.39, p=.017)$, health status $(B=.13, t=2.81$, $p=.005)$, self-efficacy $(B=.10, t=2.14, p=.033)$, and planning $(B=.23, t=5.30, p<.001)$. When past physical activity was entered in step 7 , only planning remained a significant predictor besides past behavior. In this model $33 \%$ of the variance could be explained by the variables.

\section{DISCUSSION}

Correlational findings on subjective physical age seem to be in line with previous findings on subjective age and health, showing an inverse relationship with physical activity. This might be explained by the often stated value of youth in western societies, which has been mentioned in past studies (Barak \& Stern, 1986; Montepare \& Lachman, 1989). A high level of physical fitness might be accountable for 
more youthful age identities and outdated stereotypes of aging (Montepare, 2006; Stephan, Demulier, $\&$ Terracciano, 2012). The bi-direct effect (i.e., effect can work in both directions) was also supported by a study by Knoll, Rieckmann, Scholz, and Schwarzer (2004), who reported that physical limitations after cataract surgery might be of greater importance in the construction of subjective age. This might be a result of self-evaluation of one's physical condition (cf. Montepare, 2009). Those who experience less impairment and fewer problems might feel physically younger, and are therefore more likely to engage in active lifestyles. Future research on the causality of this relationship is needed to support this hypothesis.

Future studies could also investigate the conceptual overlap between subjective (physical) age and health or quality of life dimensions more thoroughly in an age-diverse sample (cf., Spuling et al., 2013) and associated self-regulatory processes (cf., proactive coping: Gamrowska \& Steuden, 2014). More thorough investigations of potential model structures (including moderation or mediation) might help to shed more light on a potential (indirect) relationship between the age people feel physically and how active they are, as current findings provide a first indication by the intercorrelations of subjective physical age with common predictors of health behavior change and physical activity, even when controlling for chronological age and health status and checking for multicollinearity.

\section{STUDY LIMITATIONS AND FUTURE DIRECTIONS}

One limitation of this study concerns the measurement of physical activity and social cognitions by self-report. There is evidence that self-reports overestimate physical activity (Gillison, Standage, \& Skevington, 2006), but also evidence for the validity of self-reported physical activity (Miller, Freedson, \& Kline, 1994). Though the current study cannot contribute to this specific discussion, future studies should examine physical activity objectively in order to provide more validation of the current findings.

Generalization of the study results is limited due to the given sample characteristics. High dropout from $\mathrm{t} 1$ to $\mathrm{t} 2$ also leads to the suggestion that selected persons continued to participate in the study, leading to a selective subgroup of the initial sample (e.g., due to higher levels of physical activity). However, according to Frick, Bächtiger, and Reips (2001) and Reips (2002), dropout is always an issue in online research and not unusual especially when no incentives are given. Therefore, future studies could aim to retain more study participants in the study by providing incentives for continued participation (e.g., a voucher) to increase extrinsic motivation. Future studies should also be performed in change settings where interventions address social-cognitive predictors of behavior change (e.g., outcome expectancies, planning, self-efficacy) over a longer time period to especially investigate the effect direction of subjective physical age and the interplay of subjective physical age, social-cognitive predictors and physical activity.

\section{IMPLICATIONS AND CONCLUSIONS}

By studying subjective physical age as a part of health behavior processes, some implications can be drawn for future research. Our results show a slight impact of domain-specific subjective physical age on self-reported physical activity. This could imply that subjective physical age should be considered in the development of interventions targeting health behaviors, especially physical activity, as it correlates significantly with common predictors of health behavior change. Such an approach can be especially helpful for so-called tailored interventions, which are personalized by a variety of factors to increase intervention participants' commitment and adherence due to a higher personal relevance of the provided content (Hawkins, Kreuter, Resnicow, Fishbein, \& Dijkstra, 2008). Social comparison could be one approach to doing so by inducing younger subjective age identities via tailored messages or providing appropriate reference groups for comparison to intervene on subjective physical age (Stephan et al., 2013).

For health behaviors, planning and the prioritization of goals seem to be of great importance (Gollwitzer, 1993; Lippke, Wienert, Kuhlmann, Fink, \& Hambrecht, 2015; Reuter et al., 2010; Wiedemann, Lippke, Reuter, Ziegelmann, \& Schüz, 2011). Research in self-regulatory planning strategies in relation to subjective physical age and physical activity might also be of interest for future research, especially considering the given results of planning as a predictor for physical activity in the final model. The current study provides a first foundation to further investigate domain-specific subjective age constructs and their potential role in health behavior change processes.

The authors would like to thank Kureva Pritchard Matuku for editing this manuscript. This study was conducted with the support of a research grant by the Wilhelm-Stiftung für Rehabilitationsforschung.

\section{RefERENCES}

Archer, E., \& Blair, S. N. (2011). Physical Activity and the Prevention of Cardiovascular Disease: From Evolution to Epidemiology. Progress in Cardiovascular Diseases, 53, 387-396. DOI: 10.1016/j. pcad.2011.02.006
Predicting self-reported physical activity via subjective physical age 
Bandura, A. (1998). Health promotion from the perspective of social cognitive theory. Psychology and Health, 13, 623-649. DOI: 10.1080/08870 449808407422

Barak, B., \& Stern, B. (1986). Subjective age correlates: A research note. The Gerontologist, 26, 571-578. DOI: 10.1093/geront/26.5.571

Bertheussen, G. F., Romundstad, P. R., Landmark, T., Kaasa, S., Dale, O., \& Helbostad, J. L. (2011). Associations between physical activity and physical and mental health - a HUNT 3 study. Medicine \& Science in Sports \& Exercise, 43, 1220-1228. DOI: 10.1249/MSS.0b013e318206c66e

Boehmer, S. (2007). Relationships between felt age and perceived disability, satisfaction with recovery, self-efficacy beliefs and coping strategies. Journal of Health Psychology, 12, 895-906. DOI: 10.1177/1359105307082453

Bullinger, M., \& Kirchberger, I. (1998). SF-36. Fragebogen zum Gesundheitszustand. Göttingen: Hogrefe.

Caudroit, J., Stephan, Y., Chalabaev, A., \& Le Scanff, C. (2012). Subjective age and social-cognitive determinants of physical activity in active older adults. Journal of Aging and Physical Activity, 20, 484-496.

Conner, M., \& Norman, P. (2005). Predicting health behaviour: A social cognitive approach. In: M. Conner, \& P. Norman (eds.), Predicting health behaviour ( $2^{\text {nd }}$ ed.) (pp. 1-27). Maidenhead, England: Open University Press.

Demakakos, P., Gjonca, E., \& Nazroo, J. (2007). Age identity, age perceptions, and health. Annals of the New York Academy of Science, 1114, 279-287. DOI: $10.1196 /$ annals. 1396

Eibach, R. P., Mock, S. E., \& Courtney, E. A. (2010). Having a "senior moment": Induced aging phenomenology, subjective age, and susceptibility to ageist stereotypes. Journal of Experimental Social Psychology, 46, 643-649. DOI: 10.1016/j.jesp. 2010.03.002

Field, A. (2009). Discovering statistics using SPSS ( $3^{\text {rd }}$ ed.). London: Sage Publications.

Frick, A., Bächtiger, M. T., \& Reips, U.-D. (2001). Financial incentives, personal information, and dropout in online studies. In: U.-D. Reips \& M. Bosnjak (eds.), Dimensions of Internet Science (pp. 209-219). Lengerich, Germany: Pabst Science.

Galambos, N. L., Turner, P. K., \& Tilton-Weaver, L. C. (2005). Chronological and subjective age in emerging adulthood: The crossover effect. Journal of Adolescent Research, 20, 538-556. DOI: 10.1177/ 074355

Gamrowska, A., \& Steuden, S. (2014). Coping with the events of daily life and quality of life of the socially active elderly. Health Psychology Report, 2, 123-131. DOI: 10.5114/hpr.201443919

Gellert, P., Ziegelmann, J. P., Lippke, S., \& Schwarzer, R. (2012). Future time perspective and health behaviors: Temporal framing of self-regulatory processes in physical activity and dietary behaviors.
Annals of Behavioral Medicine, 43, 208-218. DOI: 10.1007/s12160-011-9312-y

Gholami, M., Knoll, N., \& Schwarzer, R. (2014). Application of the Health Action Process Approach to Physical Activity: A Meta-Analysis. Manuscript submitted for publication.

Gillison, F. B., Standage, M., \& Skevington, S. M. (2006). Relationships among adolescents' weight perceptions, exercise goals, exercise motivation, quality of life and leisure-time exercise behaviour: A self-determination theory approach. Health $E d$ ucation Research, 21, 836-847. DOI: 10.1093/her/ cyl139

Gollwitzer, P. M. (1993). Goal achievement: The role of intentions. European Review of Social Psychology, 4, 141-185. DOI: 10.1080/14792779343000059

Hawkins, R. P., Kreuter, M., Resnicow, K., Fishbein, M., \& Dijkstra, A. (2008). Understanding tailoring in communicating about health. Health Education Research, 23, 454-466. DOI: 10.1093/her/cyn004

Hubley, A. M., \& Hultsch, D. F. (1994). The relationship of personality trait variables to subjective age identity in older adults. Research on Aging, 16, 415-439. DOI: 10.1177/0164027594164005

Kleinspehn-Ammerlahn, A., Kotter-Grühn, D., \& Smith, J. (2008). Self-perceptions of aging: Do subjective age and satisfaction with aging change during old age? Journal of Gerontology: Social Sciences, 63B, 377-385.

Knoll, N., Rieckmann, N., Scholz, U., \& Schwarzer, R. (2004). Predictors of subjective age before and after cataract surgery: Conscientiousness makes a difference. Psychology and Aging, 19, 676-688. DOI: 10.1037/0882-7974.19.4.676

Koring, M., Richert, J., Lippke, S., Parschau, L., Reuter, T., \& Schwarzer, R. (2012). Synergistic effects of planning and self-efficacy on physical activity. Health Education \& Behavior, 39, 152-158. DOI: 10.1177/1090198111417621

Kotter-Grühn, D., Kleinspehn-Ammerlahn, A., Gerstorf, D., \& Smith, J. (2009). Self-perceptions of aging predict mortality and change with approaching death: 16-year longitudinal results from the Berlin Aging Study. Psychology and Aging, 24, 654666. DOI: $10.1037 / \mathrm{a} 0016510$

Kreausukon, P., Gellert, P., Lippke, S., \& Schwarzer, R. (2012). Planning and self-efficacy can increase fruit and vegetable consumption: A randomized controlled trial. Journal of Behavioral Medicine, 35, 443-451. DOI: 10.1007/s10865-011-9373-1

Lachman, M. E. (1986). Locus of control in aging research: A case for multidimensional and domain-specific assessment. Psychology and Aging, 1, 34-40.

Lippke, S., Wienert, J., Kuhlmann, T., Fink, S., \& Hambrecht, R. (2015). Perceived stress, physical activity and motivation: Findings from an internet study. Annals of Sports Medicine Research, 2, 1012. 
Lippke, S., \& Ziegelmann, J. P. (2008). Theory-based health behavior change: Developing, testing and applying theories for evidence-based interventions. Applied Psychology: International Review, 57, 698-716.

Lippke, S., Ziegelmann, J. P., Schwarzer, R., \& Velicer, W. F. (2009). Validity of stage assessment in the adoption and maintenance of physical activity and fruit and vegetable consumption. Health Psychology, 28, 183-193. DOI: 10.1037/a0012983

Maibach, E., \& Murphy, D. A. (1995). Self-efficacy in health promotion research and practice: conceptualization and measurement. Health Education Research, 10, 37-50. DOI: 10.1093/her/10.1.37

Miller, D. J., Freedson, P. S., \& Kline, G. M. (1994). Comparison of activity levels using the Caltrac accelerometer and five questionnaires. Medicine and Science in Sports and Exercise, 26, 376-382.

Montepare, J. M. (2006). Body consciousness across the adult years: Variations with actual and subjective age. Journal of Adult Development, 13, 102-107. DOI: 10.1007/s10804-007-9010-y

Montepare, J. M. (2009). Subjective age: Toward a guiding lifespan framework. International Journal of Behavioral Development, 33, 42-46. DOI: 10.1177/0165025408095551

Montepare, J. M., \& Lachman, M. E. (1989). "You're only as old as you feel": Self-perceptions of age, fears of aging, and life satisfaction from adolescent to old age. Psychology and Aging, 4, 73-78. DOI: 10.1037/0882-7974.4.1.73

Mullen, S. P., McAuley, E., Satariano, W. A., Kealey, M., \& Prohaska, T. R. (2012). Physical activity and functional limitations in older adults: the influence of self-efficacy and functional performance. The Journals of Gerontology, Series B: Psychological Sciences and Social Sciences, 67, 354-361. DOI: $10.1093 /$ geronb/gbs036

Nigg, C. R. (2005). There is more to stages of exercise than just exercise. American College of Sports Medicine, 33, 32-35.

Rademacher, J. D. M., \& Lippke, S. (2007). Dynamic online surveys and experiments with the free open-source software dynQuest. Behavioral Research Methods, 39, 415-426. DOI: 10.3758/ BF03193011

Reips, U.-D. (2002). Standards for internet-based experimenting. Experimental Psychology, 49, 243256. DOI: $10.1027 / / 1618-3169.49 .4 .243$

Reuter, T., Ziegelmann, J. P., Wiedemann, A. U., Lippke, S., Schüz, B., \& Aiken, L. S. (2010). Planning bridges the intention-behaviour gap: Age makes a difference and strategy use explains why. Psychology \& Health, 25, 873-887. DOI: 10.1080/08870440902939857

Rhodes, R. E., \& de Bruijn, G. J. (2013). How big is the physical activity intention-behaviour gap? A meta-analysis using the action control framework. British Journal of Health Psychology, 18, 296-309. DOI: 10.1111/bjhp. 12032
Salthouse, T. A. (1991). Theoretical perspectives on cognitive aging. Hillsdale, NJ: Lawrence Erlbaum.

Schwarzer, R. (2008). Modeling health behavior change: How to predict and modify the adoption and maintenance of health behaviors. Applied Psychology, 57, 1-29. DOI: 10.1111/j.14640597.2007.00325.x

Spuling, S. M., Miche, M., Wurm, S., \& Wahl, H.-W. (2013). Exploring the causal interplay of subjective age and health dimensions in the second half of life. Zeitschrift für Gesundheitspsychologie, 21, 5-15. DOI: 10.1026/0943-8149/a000084

Stephan, Y., Chalabaev, A., Kotter-Grühn, D., \& Jaconelli, A. (2013). "Feeling younger, being stronger": an experimental study of subjective age and physical functioning among older adults. The Journals of Gerontology, Series B: Psychological Sciences and Social Sciences, 68, 1-7. DOI: 10.1093/ geronb/gbs037

Stephan, Y., Demulier, V., \& Terracciano, A. (2012). Personality, self-rated health, and subjective age in a life-span sample: The moderating role of chronological age. Psychology and Aging, 27, 875880. DOI: $10.1037 / \mathrm{a} 0028301$

World Health Organization (2010). Global recommendations on physical activity for health. Retrieved from http://whqlibdoc.who.int/publications/2010/9789241599979_eng.pdf

Weiss, D., \& Lang, F. R. (2009). Thinking about my generation: Adaptive effects of a dual age identity in later adulthood. Psychology and Aging, 24, 729734. DOI: $10.1037 / \mathrm{a} 0016339$

Weiss, D., \& Lang, F. R. (2012). "They" are old but "I" feel younger: Age-group dissociation as a self-protective strategy in old age. Psychology and Aging, 27, 153-163. DOI: 10.1037/a0024887

Westerhof, G. J., \& Barrett, A. E. (2005). Age identity and subjective well-being: a comparison of the United States and Germany. The Journals of Gerontology Series B Psychological Sciences and Social Sciences, 60, 129-136. DOI: 10.1093/geronb/60.3.S129

Westerhof, G. J., \& Wurm, S. (2015). Longitudinal research on subjective aging, health, and longevity: Current evidence and new directions for research. Annual Review of Gerontology \& Geriatrics, 35, 145-166. DOI: 10.1891/0198-8794.35.145

Wiedemann, A. U., Lippke, S., Reuter, T., Ziegelmann, J. P., \& Schüz, B. (2011). The more the better? The number of plans predicts health behaviour change. Applied Psychology: Health and Well-Being, 3, 87-106. DOI: 10.1111/j.17580854.2010.01042.x

Ziegelmann, J. P., Lippke, S., \& Schwarzer, R. (2006). Subjective residual life expectancy in health self-regulation. The Journals of Gerontology Series B Psychological Sciences and Social Sciences, 61, 195-201. DOI: 10.1093/geronb/61.4.P195
Predicting self-reported physical activity via subjective physical age 